\title{
Reduced Susceptibility to Ischemia-Induced Arrhythmias in the Preconditioned Rat Heart Is Independent of PI3-Kinase/Akt
}

\author{
T. RAVINGEROVÁ, J. MATEJÍKOVÁ, D. PANCZA, F. KOLÁŘ ${ }^{1}$ \\ Institute for Heart Research, Slovak Academy of Sciences, Centre of Excellence for Cardiovascular \\ Research of the SAS, Bratislava, Slovak Republic, ${ }^{1}$ Institute of Physiology, Academy of Sciences \\ of the Czech Republic and Centre for Cardiovascular Research, Prague, Czech Republic
}

Received January 13, 2009

Accepted February 18, 2009

\section{Summary}

We examined the involvement of phosphatidylinositol 3-kinase (PI3K) and its effector protein kinase B (Akt) in cardioprotective effects of ischemic preconditioning (PC) with particular regards to its role in the protection against ischemia-induced arrhythmias in isolated perfused rat heart. PI3K/Akt inhibitor wortmannin (100 nM) was administered 15 min prior to 30-min regional (left anterior descending coronary artery occlusion) ischemia for the study of ischemic arrhythmias in the hearts perfused at constant coronary flow or prior to 30-min global ischemia followed by 2 -h reperfusion for the infarct size (IS) determination (tetrazolium staining) in the hearts perfused at constant pressure. PC procedure (one cycle of ischemia/reperfusion, $5 \mathrm{~min}$ each) significantly reduced the total number of ventricular premature complexes (PVC) and severity of arrhythmias (arrhythmia score; AS) over the whole period of left anterior descending coronary artery occlusion in comparison with non-PC controls (PVC $166 \pm 40$; AS $1.6 \pm 0.2$ vs. $550 \pm 60$ and $3.2 \pm 0.2$; respectively; $\mathrm{P}<0.05)$. In a setting of global ischemia/reperfusion, $\mathrm{PC}$ decreased IS (in \% of the left ventricle, LV) by $73 \%$. Pretreatment with wortmannin modified neither arrhythmogenesis nor IS in the non-PC hearts. Bracketing of PC with wortmannin did not abolish antiarrhythmic protection (PVC 92 $\pm 25 ;$ AS $1.7 \pm 0.2 ; \mathrm{P}<0.05$ vs. non-PC hearts). On the other hand, wortmannin increased IS/LV in the PC hearts to $24 \pm 1.2 \%$ as compared with $9 \pm 0.6 \%$ in the untreated ones $(P<0.05)$. In conclusion, PI3K/Akt inhibition did not affect reduced arrhythmogenesis during ischemia in the PC hearts indicating that in contrast to its positive role in the irreversible myocardial injury, PI3K/Akt activity is not required for protection induced by PC against ischemic arrhythmias in the rat heart.

\section{Key words}

Myocardial ischemia - Arrhythmias - Preconditioning • PI3-kinase/Akt • Rat heart

\section{Corresponding author}

T. Ravingerová, Institute for Heart Research, Slovak Academy of Sciences, POB 104, Dúbravská cesta 9, 84005 Bratislava, Slovak Republic. Fax: +421 25477 6637. E-mail: usrdravi@savba.sk

Previous studies demonstrated that phosphatidylinositol 3-kinase (PI3K) and its effector protein kinase $\mathrm{B}$ (Akt) is implicated in cell survival (Matsui and Rosenzweig 2005) and that acute PI3K/Akt activation underlies infarct size (IS)-limiting effect of ischemic preconditioning (PC) in the rat heart (Mocanu et al. 2002, Hausenloy and Yellon 2006). On the other hand, a selective inhibitor of PI3K/Akt LY294002 that suppressed protection against ischemia/reperfusion injury as documented by attenuation of both anti-infarct effect and improved functional recovery conferred by PC (Mocanu et al. 2002, Tong et al. 2000) did not abrogate protection against ischemia-induced arrhythmias in these hearts (Ravingerová et al. 2007, Matejíková et al. 2008a). In all those studies, LY294002 was used in the concentration that blocked PC-induced Akt phosphorylation (Mocanu et al. 2002, Tong et al. 2000). However, other studies revealed that, independent of PI3K-blocking effect, LY294002 in the same concentration range $(5-25 \mu \mathrm{M})$ caused inhibition of outward $\mathrm{K}^{+}$currents and changes in action potential profile in rat and mouse cardiomyocytes, via a direct 
Table 1. Effect of 15-min perfusion with wortmannin (W) on the preischemic values of heart rate (HR) and occurrence of ventricular tachycardia (VT) during 30-min ischemia in the non-preconditioned (Non-PC) and preconditioned (PC) rat hearts.

\begin{tabular}{lllll}
\hline Groups & HR (beats/min) & Incidence of VT (\%) & Total duration of VT (s) & $\begin{array}{l}\text { Number of VT } \\
\text { episodes }\end{array}$ \\
\hline Non- $P C$ & $283 \pm 11$ & 100 & $41.6 \pm 8.1$ & $12.1 \pm 2.4$ \\
Non- $P C+W$ & $295 \pm 13$ & 88 & $43.0 \pm 6.0$ & $11.2 \pm 2.0$ \\
$P C$ & $286 \pm 10$ & $20^{*}$ & $0.7 \pm 0.3^{*}$ & $0.2 \pm 0.1^{*}$ \\
$P C+W$ & $280 \pm 18$ & $12^{*}$ & $1.2 \pm 0.4^{*}$ & $1.1 \pm 0.6^{*}$ \\
\hline
\end{tabular}

Data are means \pm S.E.M. from $10-12$ hearts per group. $* \mathrm{P}<0.05$ vs. non-PC group.

blockade of voltage-dependent $\mathrm{K}^{+}\left(\mathrm{K}_{\mathrm{v}}\right)$ channels (Oudit et al. 2004, Sun et al. 2004). To discern potential PI3Kindependent electrophysiological effects of LY294002 and to verify the differential role of PI3K/Akt in the antiarrhythmic and IS-limiting effects of $\mathrm{PC}$, in the present study we used a structurally and mechanistically distinct (Walker et al. 2000) PI3K inhibitor wortmannin.

Male Wistar rats (250-300 g body weight), fed a standard diet and tap water ad libitum, were employed. All studies were performed in accordance with the Guide for the Care and Use of Laboratory Animals published by US National Institutes of Health (NIH publication No 85-23, revised 1996). After anesthesia (sodium pentobarbitone, $60 \mathrm{mg} / \mathrm{kg}$, i.p.), hearts were rapidly excised and perfused at $37^{\circ} \mathrm{C}$ in the Langendorff mode at a constant flow of $10 \mathrm{ml} / \mathrm{min} / \mathrm{g}$ (Asemu et al. 2000) or at a constant perfusion pressure of $70 \mathrm{~mm} \mathrm{Hg}$ for examination of ventricular arrhythmias or myocardial infarction, respectively. The perfusion solution was a modified Krebs-Henseleit buffer gassed with $95 \% \mathrm{O}_{2}$ and $5 \% \mathrm{CO}_{2}$ ( $\mathrm{pH}$ 7.4) containing (in $\mathrm{mM}$ ): $\mathrm{NaCl} 118.0$; $\mathrm{KCl}$ 3.0; $\mathrm{MgSO}_{4}$ 1.2; $\mathrm{NaHCO}_{3}$ 25.0; $\mathrm{NaH}_{2} \mathrm{PO}_{4}$ 1.18; $\mathrm{CaCl}_{2}$ 2.5; glucose 5.5 (Matejíková et al. 2008b). An epicardial electrogram was registered by means of two electrodes attached to the apex of the heart and the aortic cannula. Left ventricular (LV) pressure was measured by means of a non-elastic water-filled balloon inserted into the LV cavity and connected to a pressure transducer (MLP844, ADInstruments). LV developed pressure, maximal rates of pressure development and fall, heart rate, pressure-rate product and coronary flow were measured during 15-min stabilization and pre-ischemia period for the evaluation of the potential hemodynamic effects of wortmannin (100 $\mathrm{nM})$ applied for $15 \mathrm{~min}$ prior to the onset of ischemia. Heart function and arrhythmias were analyzed using PowerLab/8SP Chart 5 software (ADInstruments).
Regional test ischemia was induced by left anterior descending (LAD) coronary artery occlusion for 30 min. In the PC group, the LAD was occluded for $5 \mathrm{~min}$ followed by 5-min reperfusion prior to test ischemia. We measured the total number of premature ventricular complexes (PVC) over the whole period of ischemia, the incidence and duration of ventricular tachycardia (VT), and quantified arrhythmia severity using a 5-point scoring system (Curtis 1998).

For the evaluation of IS, in the additional subset of experiments the hearts underwent 30-min global ischemia followed by 2-h reperfusion. In the PC group, test ischemia was preceded by 5 -min ischemia followed by 5-min reperfusion. The area of infarct was determined by staining with 2,3,5-triphenyltetrazolium chloride and a computerized planimetric method as described earlier (Ravingerová et al. 2007). The IS was expressed as percentage of the LV area.

Wortmannin (Sigma) was dissolved in dimethyl sulfoxide (Lachema, Czech Republic) before being added into the perfusion medium. The final concentration of dimethyl sulfoxide was $<0.01 \%$; control hearts were treated with the same concentration of the solvent.

The data were expressed as means \pm S.E.M. One-way ANOVA and subsequent Student-NewmanKeuls test, as well as Mann-Whitney U test and Fisher's exact test were used where appropriate. Differences were considered as significant at $\mathrm{P}<0.05$.

No significant differences in the values of coronary flow and ventricular hemodynamic parameters between PC and control non-PC groups were observed at baseline and after treatment with wortmannin (data not shown). In addition, administration of wortmannin did not cause changes in the heart rate (Table 1) or morphology of epicardial electrogram in any of the groups. A fall in coronary flow by approximately $40 \%$ at the onset of regional ischemia and its increase upon 


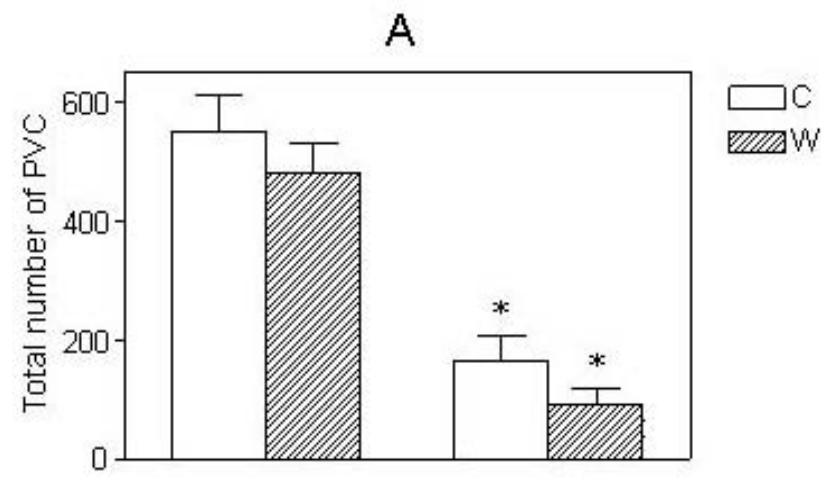

B

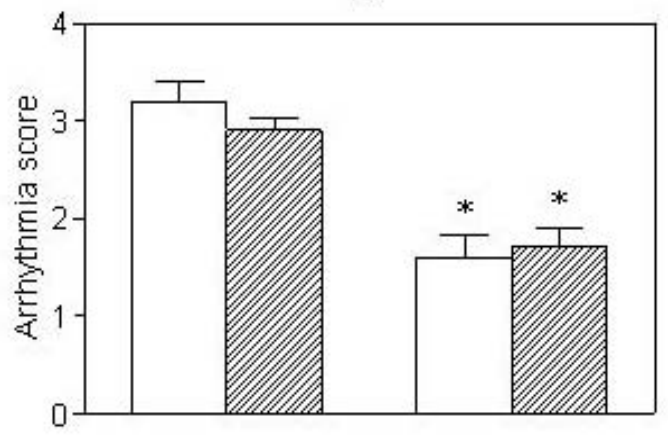

C

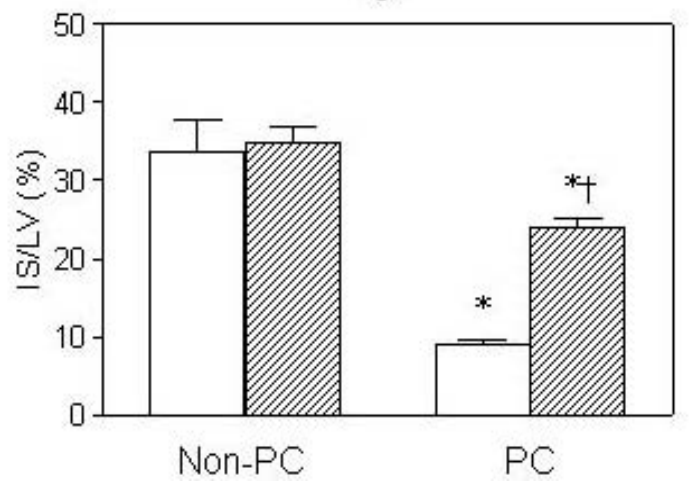

Fig. 1. Effect of wortmannin (W) on ischemia-induced ventricular arrhythmias during 30-min LAD coronary artery occlusion and the size of infarction after 30-min global ischemia and 2-h reperfusion in the non-preconditioned (Non-PC) and preconditioned $(P C)$ rat hearts. A: Number of premature ventricular complexes (PVC). B: Severity of arrhythmias (arrhythmia score). C: Size of myocardial infarction (IS) area expressed in \% of the left ventricle (LV) area. Values are means \pm S.E.M. from 10-12 hearts per group. $* \mathrm{P}<0.05$ vs. non-PC group; ${ }^{\dagger} \mathrm{P}<0.05$ vs. untreated group (C).

reperfusion were similar in all experimental groups and verified the efficacy of coronary artery occlusion.

Myocardial ischemia resulted in a high ectopic activity in the control non-PC group, and VT as the most severe form of arrhythmias occurred in all hearts. In the $\mathrm{PC}$ hearts, the total number of PVC was significantly reduced from $550 \pm 60$ to $166 \pm 40(\mathrm{P}<0.05$; Fig. $1 \mathrm{~A})$. In addition, the incidence and total duration of VT, as well as the number of its episodes were also markedly decreased (Table 1; $\mathrm{P}<0.05$ vs. non-PC controls). Accordingly, severity of arrhythmias (arrhythmia score; AS) in these hearts was much lower than in the non-PC group (1.6 \pm 0.22 vs. $3.2 \pm 0.2 ; \quad \mathrm{P}<0.05 ; \quad$ Fig. $1 \mathrm{~B})$. Administration of wortmannin did not affect arrhythmogenesis in the non-PC hearts: PVC $480 \pm 50$, AS $2.9 \pm 0.13$, VT $88 \%$ (Fig. 1A,B; Table 1). Bracketing of PC with wortmannin also failed to reverse its antiarrhythmic effect. Total number of PVC remained significantly lower $(92 \pm 25 ; \mathrm{P}<0.05$ vs. non- $\mathrm{PC}$ group; Fig. 1A). A reduced number of short episodes of VT occurred only in $12 \%$ of wortmannin -treated PC hearts $(\mathrm{P}<0.05$ vs. non-PC group; Table 1$)$, in which arrhythmia severity was decreased, similar to the untreated $\mathrm{PC}$ controls (AS 1.7 $\pm 0.19 ; \mathrm{P}>0.05$ vs. untreated $\mathrm{PC}$ group; Fig. 1B).

In the protocol of global ischemia-reperfusion, PC diminished IS from $33.7 \pm 4.0 \%$ of LV to $9.0 \pm 0.6 \%$ $(\mathrm{P}<0.05)$. Administration of wortmannin did not affect IS in the non-PC group (Fig. 1C). In contrast, in the PC hearts, presence of wortmannin abrogated cardioprotective effect and increased IS/LV to $24.0 \pm 1.2 \%(\mathrm{P}<0.05$ as compared with the untreated $\mathrm{PC}$ group; Fig. 1C).

It is proposed that acute activation of PI3K/Akt during the preconditioning phase plays an important role in cardioprotection by mediating antiapoptotic effects (Murphy 2004, Uchiyama et al. 2004). However, most of the studies are focused on the postischemic phase. In line, our results demonstrate that wortmannin, which in the same protocol of PC blocked an enhanced Akt phosphorylation before the onset of test ischemia (Barančík et al. 2008), abolished anti-infarct protection in the PC hearts. On the other hand, while electrophysiological studies established a role of PI3K/Akt in the regulation of membrane ion transport systems that determine membrane repolarization (Steinberg 2001, Gamper et al. 2002), the role of this cascade in the antiarrhythmic protection, especially during the ischemic phase of ischemia-reperfusion injury, is less elucidated. PI3K antagonists LY294002 and wortmannin that at low concentrations are considered as selective PI3K inhibitors and valuable tools for the study of cardioprotection (Oudit et al. 2004), differ in their structure and mode of action (Walker et al. 2000). LY294002 reversibly inhibits PI3K by competing with ATP for the active site of the catalytic subunit, p110 (Davies et al. 2000), while wortmannin 
irreversibly inactivates PI3K by covalent modification of its catalytic subunit (Yano et al. 1993). However, LY294002, but not wortmannin, blocks $\mathrm{K}_{\mathrm{v}}$ currents ( $\left.\mathrm{I}_{\mathrm{K} \text {,slow }}\right)$ in mouse ventricular cardiomyocytes (Sun et al. 2004) and also directly inhibits $\mathrm{K}_{\mathrm{v}}$ currents $\left(\mathrm{K}_{\mathrm{v}} 2.1\right.$ and $\left.\mathrm{K}_{\mathrm{v}} 1.4\right)$ in rat pancreatic $\beta$-cells and in various cell lines (El-Kholy et al. 2003). The channels blocked by LY294002 (including $\mathrm{K}_{\mathrm{v}} 1.5$ and $\mathrm{K}_{\mathrm{v}} 2.1$ ) are expressed in rodents (Nerbonne 2000 ) in various cell types. In particular, in rats $K_{v} 2.1$ is abundant in both pancreatic $\beta$-cells (MacDonald and Wheeler 2003) and ventricular cardiomyocytes (Barry et al. 1995) that might result in a similar response to pharmacological modulations in these tissues. In mouse and rat ventricular myocytes, LY294002 caused prolongation of action potential duration (Sun et al. 2004, Oudit et al. 2004) that might be relevant in a setting of acute ischemia and modify the occurrence of reentry arrhythmias. Nevertheless, these PI3K-independent effects do not seem to account for the failure of LY294002 to block antiarrhythmic effects of PC. Wortmannin that does not share $\mathrm{K}^{+}$channels blocking activity with LY294002 (El-Kholy et al. 2003, Sun et al. 2004) and did not affect electrical activity of the heart in the present study, had no influence on reduced arrhythmogenesis as well, although it blocked PC-induced elevation of Akt activation just prior to sustained ischemia (Barančík et al. 2008), similar to the effect of LY294002 (Mocanu et al. 2002). The latter indicates that PI3K activity is not required for antiarrhythmic effect of PC.

Our results differ from those of Hirata et al. (2005) who demonstrated that in the canine myocardium, acutely increased Akt phosphorylation led to suppression of lethal arrhythmias and limitation of IS, and wortmannin blocked both anti-infarct and antifibrillatory effects. However, that study was focused on the postischemic injury and reperfusion-induced arrhythmias which differ from those induced by ischemia. Thus, besides differences between the species and end-points of protection, the differences between the mechanisms of different types of arrhythmias occurring during ischemia and reperfusion (Curtis and Hearse 1989) should also be taken into consideration when susceptibility to arrhythmias is to be characterized.

In conclusion, bracketing of PC with an irreversible PI3K/Akt inhibitor wortmannin, that abolished protection against lethal myocardial injury, did not reverse protection against ventricular arrhythmias conferred by PC during sustained ischemia, corroborating our previous findings of the LY294002-independent protection against ischemia-induced arrhythmias in the preconditioned rat heart. Thus, taken together our results indicate that enhanced tolerance to ischemic arrhythmias in the PC hearts does not appear to be mediated by PI3K/Akt suggesting that PI3K/Akt activity may play distinct roles in the IS limitation and antiarrhythmic protection.

\section{Conflict of Interest}

There is no conflict of interest.

\section{Acknowledgements}

The authors are thankful to Mrs. I. Blažíčková and I. Formánková for their excellent technical assistance. This study was supported by grants VEGA SR 2/0173/08, APVV SK-CZ-0049-07 and GACR 305/07/0875.

\section{References}

ASEMU G, NECKÁŘ J, SZÁRSZOI O, PAPOUŠEK F, OŠŤÁDAL B, KOLÁŘ F: Effects of adaptation to intermittent high altitude hypoxia on ischemic ventricular arrhythmias in rats. Physiol Res 49: 597-606, 2000.

BARANČÍK M, IVANOVÁ M, MATEJÍKOVÁ J, ŠPÁNIKOVÁ A, RAVINGEROVÁ T: Mechanisms involved in wortmanin-induced modulation of ischemic tolerance in rat hearts. Physiol Res 57: 9P, 2008.

BARRY DM, TRIMMER JS, MERLIE JP, NERBONNE JM: Differential expression of voltage-gated $\mathrm{K}^{+}$channel subunits in adult rat heart. Relation to functional $\mathrm{K}^{+}$channels? Circ Res 77: 361-369, 1995.

CURTIS MJ: Characterisation, utilisation and clinical relevance of isolated perfused heart models of ischaemia-induced ventricular fibrillation. Cardiovasc Res 39: 194-215, 1998.

CURTIS MJ, HEARSE DJ: Ischemia-induced and reperfusion-induced arrhythmias differ in their sensitivity to potassium: implications for the mechanisms of initiation and maintenance of ventricular fibrillation. $J \mathrm{Mol} \mathrm{Cell}$ Cardiol 21: 21-40, 1989.

DAVIES SP, REDDY H, CAIVANO M, COHEN P: Specificity and mechanism of action of some commonly used protein kinase inhibitors. Biochem J 351: 95-105, 2000. 
EL-KHOLY W, MACDONALD PE, LIN JH, WANG J, FOX JM, LIGHT PE, WANG Q, TSUSHIMA RAG, WHEELER MB: The phosphatidylinositol 3-kinase inhibitor LY294002 potently blocks $\mathrm{K}_{\mathrm{v}}$ currents via a direct mechanism. FASEB J 17: 720-722, 2003.

GAMPER N, FILLON S, HUBER SM, FENG Y, KOBAYASHI T, COHEN P, LANG F: IGF-I up-regulates K ${ }^{+}$ channels via PI3-kinase, PDK1 and SGK1. Pflügers Arch 443: 625-634, 2002.

HAUSENLOY DJ, YELLON DM: Survival kinases in ischemic preconditioning and postconditioning. Cardiovasc Res 70: 240-253, 2006.

HIRATA A, MINAMINO T, ASANUMA H, SANADA S, FUJITA M, TSUKAMOTO O, WAKENO M, MYOISHI M, OKADA K, KOYAMA H, KOMAMURA K, TAKASHIMA S, SHINOZAKI Y, MORI H, TOMOIKE H, HORI M, KITAKAZE M: Erythropoietin just before reperfusion reduces both lethal arrhythmias and infarct size via the phosphatidylinositol-3 kinase-dependent pathway in canine hearts. Cardiovasc Drugs Ther 19: 3340, 2005.

MACDONALD PE, WHEELER MB: Voltage-dependent $\mathrm{K}^{+}$channels in pancreatic beta cells: role, regulation and potential as therapeutic targets. Diabetologia 46: 1046-1062, 2003.

MATEJÍKOVÁ J, NECKÁŘ J, KOLÁŘ F, RAVINGEROVÁ T: Suppression of ischemic arrhythmias in the diabetic heart does not require PI3K/Akt and ROS: relevance to ischemic preconditioning. J Mol Cell Cardiol 44: 761762, 2008a.

MATEJÍKOVÁ J, KUCHARSKÁ J, PANCZA D, RAVINGEROVÁ T: The effect of antioxidant treatment and NOS inhibition on the incidence of ischaemia-induced arrhythmias in the diabetic rat heart. Physiol Res 57 (Suppl 2): S55-S60, 2008b.

MATSUI T, ROSENZWEIG A: Convergent signal transduction pathways controlling cardiomyocyte survival and function: the role of PI3-kinase and Akt. J Mol Cell Cardiol 38: 63-71, 2005.

MOCANU MM, BELL RM, YELLON DM: PI3 kinase and not p42/p44 appears to be implicated in the protection conferred by ischemic preconditioning. J Mol Cell Cardiol 34: 661-668, 2002.

MURPHY E: Primary and secondary signaling pathways in early preconditioning that converge on the mitochondria to produce cardioprotection. Circ Res 94: 7-16, 2004.

NERBONNE JM: Molecular basis of functional voltage-gated $\mathrm{K}^{+}$channel diversity in the mammalian myocardium. J Physiol 525: 285-298, 2000.

OUDIT GY, SUN H, KERFANT B-G, CRACKOWER MA, PENNINGER JM, BACKX PH: The role of phosphoinositide 3-kinase and PTEN in cardiovascular physiology and disease. J Mol Cell Cardiol 37: 449471, 2004.

RAVINGEROVÁ T, MATEJÍKOVÁ J, NECKÁŘ J, ANDELOVÁ E, KOLÁŘ F: Differential role of PI3K/Akt pathway in the infarct size limitation and antiarrhythmic protection in the rat heart. Mol Cell Biochem 297: 111-120, 2007.

SUN G, OUDIT GY, RAMIREZ RJ, COSTANTINI D, BACKX PH: The phosphoinositide 3-kinase inhibitor LY294002 enhances cardiac myocyte contractility via a direct inhibition of $I_{\mathrm{k}, \text { slow }}$ currents. Cardiovasc Res 62 : 509-520, 2004.

STEINBERG SF: PI3King the L-type calcium channel activation mechanism. Circ Res 89: 641-644, 2001.

TONG H, CHEN W, STEENBERGEN C, MURPHY E: Ischemic preconditioning activates phosphatidylinositol-3kinase upstream of protein kinase C. Circ Res 87: 309-315, 2000.

UCHIYAMA T, ENGELMAN RM, MAULIK N, DAS DK: Role of Akt signaling in mitochondrial pathway triggered by hypoxic preconditioning. Circulation 24: 3042-3049, 2004.

WALKER EH, PACOLD ME, PERISIC O, STEPHENS L, HAWKINS PT, WYMANN MP, WILLIAMS RL: Structural determinants of phosphoinositide 3-kinase inhibition by wortmannin, LY294002, quercetin, myricetin, and staurosporine. Mol Cell 6: 909-919, 2000.

YANO H, NAKANISHI S, KIMURA K, HANAL N, SAITOH Y, FUKUI Y, NONOMURA Y, MATSUDA Y: Inhibition of histamine secretion by wortmannin through the blockade of phosphatidylinositol 3-kinase in RBL-2H3 cells. J Biol Chem 268: 25846-25956, 1993. 